\title{
TRUE GRIT AND THE POSITIVITY OF FAITH
}

\author{
Finlay Malcolm ${ }^{1}$ and Michael Scott ${ }^{2}$ \\ ${ }^{1}$ University of Hertfordshire; ${ }^{2}$ University of Manchester
}

Original scientific article - Received: 02/10/2020 Accepted: 24/01/2021

\begin{abstract}
Most contemporary accounts of the nature of faith explicitly defend what we call 'the positivity theory of faith' - the theory that faith must be accompanied by a favourable evaluative belief, or a desire towards the object of faith. This paper examines the different varieties of the positivity theory and the arguments used to support it. Whilst initially plausible, we find that the theory faces numerous problematic counterexamples, and show that weaker versions of the positivity theory are ultimately implausible. We discuss a distinct property of faith that we call 'true grit', such that faith requires one to be resilient toward the evidential, practical, and psychological challenges that it faces. We show how true grit is necessary for faith, and provides a simpler and less problematic explanation of the evidence used to support the positivity theory.
\end{abstract}

Keywords: Propositional faith; objectual faith; desire; evaluative belief; positive attitude

\section{Introduction}

Does faith require a positive attitude towards the object of faith? That is, does faith require that one desire or approve of the object of one's faith, or regard it as a good or desirable thing? Accounts of faith that endorse this position, which we will call positivity theories, are prevalent in recent literature in the field. A widely canvassed type of argument for positivity theory appeals to examples that appear to show that faith, in contrast with 
belief or acceptance, must be accompanied by a positive attitude. For example,

1. Ava believes in ghosts.

2. Ava believes that Donald Trump will win a second term in 2020 .

are attitudes that Ava could have even if she thought that ghosts are malevolent beings, or that Trump winning a second term would be a bad thing. In contrast,

3. Ava has faith in ghosts.

4. Ava has faith that Donald Trump will win a second term in 2020.

seem to require that Ava positively evaluate ghosts or Trump winning. Moreover, expressions of faith directed toward objects that the speaker does not consider favourably such as

5. I have faith in our impending demise.

6. I have faith that Donald Trump will destroy the world.

look like infelicitous or inapt things to say. The positivity theory is usually advanced with some version of these arguments. The theory is sometimes restricted to significant varieties of faith, such as religious or propositional faith, and there are differences in how the positive valency metaphor is cashed out, be it in terms of desires or evaluative beliefs. However, most recent accounts of faith support a version of positivity theory; no contemporary account, to our knowledge, rejects it.

We will review in section one the positivity thesis in its different forms and in section two the arguments put forward in its defence. We agree that faith and a positive evaluation of its content are closely associated but argue, partly on the basis of counterexamples set out in section three, that this is a contingent rather than a necessary relation. While there are some fallback positions available to the theory, which we will explore in section four, the proposed necessary connection between faith and a positive evaluation of its object or content should be rejected. Moreover, in section five, we argue that there are other widely acknowledged properties of faith that provide a simpler explanation for why faith often goes along with a positive attitude. Specifically, a property of faith we call true grit: its relationship with a disposition to resist epistemic, practical and psychological considerations to give up on the object or content of faith. True grit, we argue, does justice to both the examples and intuitions that motivate positivity theory without the requirement that faith be accompanied by a positive attitude. 


\section{What is Positivity Theory?}

Positivity theories are commonly focussed on propositional faith, where faith is an attitude with a propositional content; for example, faith that God is good, that Brazil will win the World Cup, or that things will turn out well. According to Robert Audi:

even if propositional faith is not reducible to a kind of belief, it is reducible to a complex of beliefs and attitudes, for example to some degree of belief that $\mathrm{p}$ and a positive attitude toward p's being the case. $(2011,79)$

As Audi indicates here, positivity is seen as a way to distinguish faith from cognate propositional attitudes such as belief. ${ }^{1}$ Positivity theory is also often advanced for objectual faith, or faith-in $S$, where faith has a nonpropositional object such as a person, an institution, or political system. According to Audi:

There is a further characteristic (already foreshadowed) of both propositional and...[objectual] faith. Both require a positive evaluative attitude toward their object. $(2011,67)$

Others who take positive valency as essential for faith include William Alston (1996, 12), Lara Buchak (2014, 53), Daniel Howard-Snyder (2017, 56-57), Walter Kaufman $(1958,113)$ and John Schellenberg $(2005,133)$. Less boldly, Daniel McKaughan (2018, 198) says positivity is a characteristic of 'paradigm cases' of faith-that and faith-in. Alvin Plantinga, mainly concerned with Christian faith, claims that someone with Christian faith '(paradigmatically) finds the whole scheme of salvation enormously attractive, delightful, moving, a source of amazed wonderment' $(2000,292)$. Although 'paradigmatic' is open to interpretation, we take this to be the view that positivity is necessary for some broad but restricted (in some to-be-specified way) class of faith states.

\footnotetext{
${ }^{1}$ Whether propositional faith requires belief or, more modestly, acceptance, is a matter of contention. On a standard view, to accept a proposition is to use it as if it were true in one's theoretical and practical reasoning (Cohen 1992; Jackson forthcoming); one can choose to accept $p$ even if one does not believe it to be true. The accounts of acceptance somewhat differ, however. Even though Alston's (1996) account of acceptance draws from Cohen (1992), he diverges from Cohen by maintaining that acceptance is "not just on an "as if" basis... To accept $[p]$ is to accept $[p]$ as true' (18), rather than accepting $p$ as if $p$ were true. For the purposes of evaluating the positivity theory, whether faith requires belief or acceptance is not crucial: comparable arguments and examples about the differences between faith and belief can be constructed for faith and acceptance. For simplicity, therefore, we will take belief to be the cognitive constituent of faith.
} 
Alston draws attention to two different ways in which faith is positive. He notes that merely believing $p$ can be considered a 'positive attitude' towards $p$ (Alston 1996, 12) but the positivity of faith is something different:

It necessarily involves some pro-attitude toward its object. If S is said to have faith that democracy will eventually be firmly established everywhere, that implies not only that $S$ believes that this will happen but that $\mathrm{S}$ looks on this prospect with favor. If $S$ were strongly opposed to universal democracy, it would be somewhere between inapt and false to represent $S$ as having faith that democracy will triumph. Whereas one can truly and unproblematically be said to believe that democracy will win out even if one views the prospect with horror. (Alston $1996,12)^{2}$

Let's call the positivity of belief B-positivity. In what way is B-positivity positive? What Alston has in mind, we take it, is that believing $p$ to be true includes, among many other things, the disposition to use $p$ in one's reasoning and to endorse or assert $p$ in various circumstances. Belief that $p$ is thereby 'positive' because the believer is disposed to rely on and agree with it. ${ }^{3}$ In contrast, disbelief goes along with the 'negative' dispositions to disagree with and reject $p$. However, as Alston makes clear, the kind of positive attitude that he is interested in is not B-positivity. Audi makes a similar point:

If I have faith that God loves human beings, I have not just a cognitive attitude (the kind that, like belief, may be called true or false), but something more: a certain positive disposition toward the state of affairs being so, i.e. actually obtaining (toward the truth of the proposition, in another terminology). (Audi 2011, 54)

Call this second kind of positivity F-positivity. F-positivity and Bpositivity are distinct properties. B-positivity towards $p$ is not only compatible with a lack of F-positivity towards $p$, but also a negative evaluation of $p$. So, someone who believes that democracy will be universally established is B-positive towards that proposition but may be entirely neutral about that prospect or even, as Alston notes, 'regard it with

\footnotetext{
${ }^{2}$ As noted in footnote 1 , Alston's view is that faith requires either belief or acceptance.

${ }^{3}$ In line with fn. 1 above, a similar positive attitude may characterise acceptance; acceptance that $p$ similarly involves the disposition to use $p$ in one's reasoning and to endorse or assert $p$ under various circumstances and so may similarly be understood to share B-positivity. Indeed, although Alston presents positivity as a characteristic of belief, he endorses an acceptance theory of faith (Alston 1996).
} 
horror' (cf. also Howard-Snyder, 2019, 5). It is F-positivity that is being posited in the positivity theory and that is the focus of these arguments and of this paper.

What, then, is F-positivity? For Alston, it is 'some pro-attitude towards its object'. Here are some other proposals:

This is an attitude of a kind that at least normally has motivational as well as cognitive elements. The point is (roughly) that faith that something will occur entails taking that to be a good thing. (Audi 2011, 67)

A positive conative orientation toward the object of faith consists in being for its truth, favoring its being the case, wanting it to be so, giving its truth a positive evaluation, regarding it as good or desirable, and the like. (Howard-Snyder 2017, 48)

some sort of...positive affective-evaluative attitude toward the person or content that is the object of one's faith...someone who has faith that God exists or that God will be faithful to such and such promises will care about whether the propositions in question are true, will want them to be the case, or will consider the truth of these propositions or the obtaining of these states of affairs to be good or desirable. (McKaughan 2018, 198)

And according to John Schellenberg

it seems possible to develop examples of cases where one has faith that $p$ without a desire that $p$ be true. Accordingly, so as not to be misleading, I suggest that we avoid the notion of a pro-attitude and instead deploy the weaker notion of a favourable evaluation of the state of affairs reported by $p$ (and, by extension, of the truth of $p$ ). This is entailed by faith that $p$. $(2005,133)$

There are significant differences in these accounts of F-positivity. To see this, consider some different options for analysing the belief/desire constituents of F-positivity. ${ }^{4}$ Suppose that $R$ has faith that $p$ (or faith in $\mathrm{s}$ ). On a belief theory of F-positivity:

\footnotetext{
${ }^{4}$ This paper will follow these authors in working within the framework of Humean or belief-desire psychology that distinguishes between beliefs and desires as categories of mental state with distinct
} 
BEL: $R$ believes that $p$ is good or that it is desirable that $p$ be true (or believes that $s$ is good or desirable).

And according to the desire theory of F-positivity:

DES: $R$ desires that $p$ or approves of $p$ (or desires/approves of $s)$.

Either one of these conditions could be understood as providing a complete analysis of positivity, as follows:

X-BEL: Only BEL is true

$\mathrm{X}$-DES: Only DES is true

There are also two obvious ways of combining them:

CON: Both BEL and DES are true

DIS: Either BEL or DES are true

Alston is completely clear on where he stands, at least with respect to propositional faith. He supports a pure desire account, i.e. X-DES. Audi proposes that the positivity of faith only requires one to regard the object of faith as a good thing, which he seems to allow could be either an evaluative belief or a desire. Schellenberg clearly rejects X-DES but his preferred notion of 'favourable evaluation' appears to encompass either desire or belief. So, we take both authors to support DIS. In other work, Howard-Snyder $(2013,367)$ adopts a varied stance towards positivity, and so is likely also a supporter of DIS. Similarly, McKaughan also gives space to positive evaluations that could be interpreted as either desires or beliefs about $p$ (i.e. as approving of $p$ or believing that $p$ is a good thing).

There is a reason for thinking, contrary to X-DES and CON, that Fpositivity need not be a desire-like attitude. Adapting an example from John Schellenberg, imagine that Paul is a supporter of a political party and places his faith in its leadership. Following a leadership contest, not only does Paul's preferred candidate fail to win, the successful candidate is someone that Paul finds both personally repellent and morally

\footnotetext{
dispositional profiles. This is sometimes put in terms of direction of fit. Desires (and desire-like states such as wishes, hopes, plans and so on) have a world-to-mind direction of fit: the agent desires to bring the world into accordance with the content of the desire. Beliefs have a mind-to-world direction of fit: the content of the belief should fit with the way that the world is. Desires, unlike beliefs, are taken to motivate the agent to bring about action.
} 
reprehensible. Despite his misgivings and resentment of the candidate's success, Paul recognises that the new leader is the best prospect for achieving the aspirations of the political party. Accordingly, Paul maintains his faith in the leadership, and loyally commits to campaign for it. As Schellenberg points out, faith can be positive by virtue of recognising that the object of faith is desirable without any favourable feelings towards it: 'something may intellectually be seen as desirable - as worthy of desire - without actually being desired, when relevant psychological obstacles are present' $(2005,133)$.

For these reasons, we take the positivity theorists to be committed to (at least) the more modest DIS. The availability of plausible counterexamples to X-DES and CON make DIS the more plausible position. ${ }^{5}$

To sum up, positivity theorists support a theory on the following lines:

Positivity Theory (PT). Necessarily, if $\mathrm{R}$ has faith that $p$ (or in $s$ ) then $\mathrm{R}$ desires that or approves of $p$ (or desires or approves of $s$ ), or believes that $p$ (or $s$ ) is good or desirable.

Additionally, some restrict PT to religious faith or to paradigm cases of faith.

Before proceeding, we need one further distinction. It is very widely held that faith motivates the agent with faith (e.g. Bishop 2007, 117; HowardSnyder 2017, 56-57; Schellenberg 2005, 127-66; Swinburne 2001, 211). This theory, which we will call faith internalism, ${ }^{6}$ in its simplest form says that

Necessarily, if $\mathrm{R}$ has faith that $p$ or faith in $s$, then $\mathrm{R}$ is (to some extent) motivated to act on that faith.

Now, faith internalism could dovetail with PT in the following way. Suppose that the motivation to act is explained by the presence of a desirelike, or evaluative state, in line with Humean psychology (see footnote 4). It follows from faith internalism that faith must be accompanied by a desire-like attitude. This affords a neat way of bringing together positivity theory and faith internalism: the desire towards or approval of the object of faith posited by PT could also motivate the agent. Audi (2011, 67, cf. also Howard-Snyder 2019, 3) appears to suggest this connection. Faith internalism and positivity theory are clearly distinct theories. However,

\footnotetext{
${ }^{5}$ Note that if the F-positivity of propositional faith is cashed out as an evaluative belief, it will involve two positive cognitive attitudes: belief in the propositional content (which is B-positive) and belief that that the content is good (which is F-positive).

${ }^{6}$ For an overview of a comparable current debate in metaethics see Björnsson et. al. (2015).
} 
since the connections between them play a role in later discussion it is useful to make clear at this stage that these theories are independent. There are three main reasons for this.

First, PT can be satisfied by faith being accompanied by evaluative beliefs (i.e. BEL) about the object of faith rather than desires. So, positivity theory (assuming, again Humean psychology) is compatible with faith being motivationally inert. Second, the desire-like state that motivates the agent with faith does not have to be about the object of faith, as PT requires. Suppose that Jane has faith that Brazil will win the next World Cup. She enthusiastically supports the team but she is motivated by a desire to please her father (who is a big supporter of the Brazilian team) rather than a desire that the team wins. She may not be aware that this is the desire that motivates her. Her psychological state satisfies faith internalism - she supports the team - but not PT because her motivating desire is not directed towards the content of faith. Third, faith internalism does not require that the desire-like state that motivates the agent with faith is positive. Suppose, to take a minor variation on our example, that Jane is motivated by a fear of her father's displeasure (and he would be displeased if Brazil lost). Again, she may not be aware that this is the desire that is motivating her to support the team. Unlike PT, faith internalism is not picky on the kind of attitude that motivates the agent to act on her faith. The attitude does not have to be positive evaluation or approval - it could be fear, selfishness, vanity, etc. - provided that it disposes the agent to act on that faith.

It can be seen, therefore, that while an agent whose faith involves a positive and motivating evaluation of the object of faith will satisfy both PT and faith internalism, these two theories are independent.

\section{Arguments for the Positivity of Faith}

A useful initial classification among the arguments advanced for positivity theory is between those that exploit (a) examples of the kinds of attitudes that are appropriately regarded as faith, and (b) examples that contrast faith with related attitudes.

Examples of (a) are found in the writings of Walter Kaufmann, one of the first philosophers to draw attention to positivity: 'One can say: "I have faith I shall recover." One cannot say, without doing violence to language: "I have faith that I have cancer." $(1958,113)$. Lara Buchak takes a similar approach. According to Buchak, 
in order for a proposition to be a potential object of faith [...] the individual must have a positive attitude towards the truth of the proposition. This can be seen by noting that while I can be said to have or lack faith that you will quit smoking, I can't appropriately be said to have or lack faith that you will continue smoking. $(2014,53)$

Positivity theory is taken to be supported by (a) because genuine faith appears to go along with a positive evaluation of its object. Examples of (b) are particularly prominent in discussion of propositional faith and point up differences between faith that $p$ and other propositional attitudes, in particular belief. Alston's example of the difference between faith and belief that democracy will triumph is a case in point. Faith that $p$, it seems, must have an extra 'positive' property not necessary for mere belief that $p$. As is clear from the quotations above, the arguments for positivity theory employ two different types of evidence. Some arguments (c) use examples of faith and related attitudes to bolster intuitions about the kind of thing that faith is, while others (d) appeal to considerations about linguistic felicity. Buchak and Kaufmann, for instance, emphasise the oddity of saying that someone has faith if they don't also have a positive attitude toward the object. Alston appeals to either (c) or (d) considerations: it is 'somewhere between inapt and false' to say that S has faith that democracy will triumph if $S$ does not see that prospect favourably. The strategy of (d), we take it, is that if there is something linguistically amiss with representing someone as having faith without an associated positive attitude, that supports the conclusion that the positivity is built into our concept of faith. ${ }^{7}$

We think that (c) is a more compelling strategy than (d). First, as Malcolm and Scott (2017) point out, it is questionable not only whether judgements made by hearers about linguistic felicity offer reliable evidence for a philosophical theory about the nature of faith, but also whether hearers are expressing linguistic intuitions rather than theoretical presuppositions. ${ }^{8}$ Second, and more directly, the assumption that the proposed statements about faith are infelicitous seems to us unpersuasive. Take Buchak's and Kafumann's claims that

\section{I have faith that you will continue smoking}

\footnotetext{
${ }^{7}$ The notion of linguistic felicity is not fully spelled out by proponents of these arguments. It appears to be determined by the evaluation, by competent speakers of a language, that a given sentence of that language is ill-formed or does not make sense.

${ }^{8}$ For a review of the many challenges in unpicking facts about meaning from the judgments of speakers about linguistic felicity see Novek (2018). An empirically informed investigation into talk of faith, of the kind conducted in experimental pragmatics, is an intriguing but as yet unexplored prospect.
} 


\section{I have faith that I have cancer}

are linguistically infelicitous. We agree that these are unusual things to say (indeed, sufficiently unusual that a hearer might reasonably ask 'don't you mean believe rather than have faith?') but that is because what they are saying is so unusual rather than because there is something wrong with the utterances. Even by the positivity theorist's own lights these utterances could be true, provided that the speaker has a positive attitude towards the hearer's continuing to smoke or the speaker's having cancer. It might be morally or prudentially inappropriate to assert (7) or (8) but neither are linguistically infelicitous. Alston proposes that

9. S has faith that universal democracy will triumph but is strongly opposed to it

is inapt. But this does not seem to involve any linguistic mistake even if (assuming Alston is right and faith necessarily involves a pro-attitude) $\mathrm{S}$ cannot have the combination of attitudes described by (9). Alston would presumably wish to maintain that we can understand (9) to argue that it is saying something untrue. Indeed, this may be his point: (9) is inapt not in the sense that its meaning is unclear or that it deploys a misuse of language but that it is obviously untrue. For these reasons, we take (c) to offer the most promising way of arguing for PT. ${ }^{9}$

\section{Faith without Positivity}

Having considered what positivity is and the arguments for the positivity theory, is PT true? We believe that faith often goes along with a positive attitude but that the connection is contingent rather than necessary. That is, we support the more modest theory:

(PT*): Faith is usually but contingently accompanied by positive attitudes towards its object or content.

We will flesh out the details of this contingent relationship later in the paper; our focus here is on whether the necessary connection between faith and positive attitudes is defensible. In this section we will set out several counterexamples to PT; in the following we will look at two ways of revising PT to accommodate these counterexamples. Space considerations

\footnotetext{
${ }^{9}$ The case for PT is sometimes advanced alongside one for faith internalism (Audi 2011, 67; HowardSnyder 2019, 3). However, as we have seen, these are independent theories; we will return to the connections between them in section four.
} 
limit the range and number of counterexamples we can give, and we have found in discussion that interlocutors vary in how intuitively appealing they find the given putative examples of faith. Our aim, therefore, is to raise doubts for the reader about the simplicity or necessity of a relation between faith and positivity and to motivate consideration of an alternative account.

A commonplace observation about faith is that it is frequently accompanied by misgivings, either about the object or content of faith. Faith can be difficult to maintain and is often talked about as something that individuals struggle with. This aspect of faith has been a focus of discussion in recent papers in the field (not least by some of the supporters of positivity theory), with most attention being given to how faith is maintained in the face of doubt (Pojman 1986; Schellenberg 2005; Howard-Snyder 2013; McKaughan 2013, 2018). We find similar considerations raised in historical and theological treatments of religious faith. According to one recent survey of religious faith, "[d]oubt emerged as inevitable, as concomitant to faith, occasionally a virtue, more often as a struggle, an ailment to be overcome" (Andrews 2016, 2). However, the kinds of misgivings that go along with faith clearly extend beyond doubts about the truth of one's faith. ${ }^{10}$ Religious faith may be clouded by despair, torment, anger, feelings of abandonment, sadness and dark nights of the soul. As McKaughan (2018) has demonstrated, such feelings were widely felt and documented by Mother Theresa. For instance, in her personal diaries from around 1961 she writes,

Since [19]49 or [19]50 this terrible sense of loss - this untold darkness - this loneliness this continual longing for Godwhich gives me that pain deep down in my heart-Darkness is such that I really do not see-neither with my mind nor with my reason - the place of God in my soul is blank-There is no God in me-when the pain of longing is so great-I just long \& long for God - and then it is that I feel- He does not want me-He is not there. (Kolodiejchuk 2007, 349)

More generally, it seems, during a crisis of faith, that negative feelings about the content or object of faith can come to the fore while positive feelings and judgments can go into abeyance, even if only for brief periods. The insistence on positivity as a necessary condition for faith seems at odds with this view about crises of faith. Moreover, crises of faith are not only restricted to religious cases. For example, one can continue to have faith in a person who engages in frustrating and self-destructive behaviour, even

\footnotetext{
${ }^{10}$ For some recent empirical data see Dura-Vila (2016).
} 
though this behaviour may cause one to doubt the merits of one's faith and to feel anger towards and disappointment in that person.

The problem presented for PT by crises of faith is straightforward: faith in crisis can become detached, if only briefly, from positive evaluations or beliefs about the object or content of that faith. We do not, however, regard these cases as losses of faith. Indeed, faith is often seen as helping one to get through such crises. This does not, of course, establish that there is no connection between faith and positive evaluations. It does show, however, that PT as it stands is untenable. Faith is not indefatigably positive: it may endure even when positive attitudes about the object or content of faith are in abeyance.

If objectual and propositional faith is possible without a positive attitude when faith is in crisis, can they also come apart in less challenging circumstances? Consider the following example.

[A] Ellis is travelling to a conference in Shanghai where he is due to deliver a presentation. Ellis does not know the country and his flight schedule leaves him little time to get from the airport to the conference venue. But his old friend Thomas, who works in China, has agreed to pick him up at the airport to drive him to the event. Ellis, who regards Thomas not only a good friend but also a conscientious person, has faith in Thomas to be there to collect him on time and get him to the conference (as well as propositional faith that Thomas will do these things). Over the course of the flight, however, Ellis spots a major problem with the presentation, one that he cannot clear up in the time he has. If only, Ellis thinks, Thomas could slack off on this occasion and be a little late and I could miss the presentation slot and save the embarrassment of a poor presentation. He retains his faith with respect to Thomas collecting him and getting him to the venue on time but he neither believes these would be good things, nor does he desire them.

If the positivity theory is right, Ellis should have lost his faith in Thomas over the course of the flight. But this does not seem right. In key respects Ellis' attitudes and dispositions are unchanged. He has not undergone loss of confidence in Thomas: he stills expects Thomas to be there on time, he has not made any alternative plans so still relies on Thomas to be there on time. It is simply that, with respect to some things that Ellis has faith in Thomas to do, he has changed his evaluation of their merit: he doesn't positively evaluate Thomas' timeliness in this context. Ellis' hope that 
Thomas be late is perhaps unfair to Thomas since Ellis' predicament is his own fault, but it seems possible. Ellis might even say things like: 'While I have full faith in Thomas to pick me up from the airport and get me to the conference on time, I hope he doesn't'. We would be puzzled if Ellis said: 'Since looking again at my presentation, I've totally lost faith in Thomas getting me to the venue on time'. More generally, faith can persevere even though one's positive attitudes about its content or object do not. Contrary to PT, it seems possible to have faith in $\mathrm{s} x$-ing (or faith that $\mathrm{s} x \mathrm{~s}$ ) while lacking a positive attitude toward the object or content.

Consider two further, connected examples:

[B] Silvia has faith that the Biblical miracle stories are true. However, she has always been troubled by the story of the Miracle at Cana. She does not understand why Jesus would have transformed water into wine; it seems to her a pointless exercise. Moreover, she disapproves of drunkenness and the encouragement thereof. She retains her faith that Jesus transformed water into wine at Cana, along with her faith in the other miracle stories, despite neither believing that it was a good thing to do nor approving of it.

[C] Ryan has faith that the teachings of his church are based on the word of God. However, he finds some of these teachings a struggle, in particular those related to the sinfulness of homosexuality. This is because Ryan is coming to terms with the fact that he is gay. Ryan has faith that the church's teachings on homosexuality are true but he does not look on them with any favour; he certainly does not desire them to be true, nor, given his own experiences, does he understand how God could will them. Nevertheless, his faith holds.

Silvia, insofar as she has a view of the content of her faith, considers the miracle ethically dubious. Ryan struggles with his faith and is unable to look positively on some aspects of it. Both are examples of faith without DIS. The cases are connected because they trade on the fact that faith is often directed towards a body of propositions to which agents are committed, rather than just one. Religious faith may encompass numerous propositions, sometimes codified in creeds, commitment to which are considered important to membership in a religious tradition. Political systems, particularly those associated with revolutionary movements, provide another example. In such cases, the agent may not view all of the requisite propositions with the same favourable attitude; some may be seen either neutrally but taken on trust as among the requisite commitments of 
the political position. Faith that $p$, that $q$, that $r$, etc., therefore seems possible without a positive attitude towards all of the propositions in question.

Consider one more example:

[D] Martha has faith that those people that God does not save will go to Hell and that such decisions are predestined. She does not claim to understand how this arrangement can be just or good; her faith is such that she eschews questions about its merits or thinking through its ethical implications. Nor does she desire it to be true; indeed, her feelings towards this are closer to dread, not least in case she should be among those who are not saved.

Martha's faith is not in crisis; she has not had her positive attitudes challenged or upset. Indeed, Martha might never have seen predestination in a positive light but as an incomprehensible mystery, or as an inescapable fact of religious reality about which she makes no evaluative judgement. Her faith is manifested by her resolute conviction that this is part of a religious reality, and that this conviction manifests in her life and thinking, rather than her approving of it. Moreover, her lack of a positive stance might be deliberate: she intends to refrain from forming an evaluative appraisal of predestination because she thinks it at best a pointless or at worst inappropriately presumptive attitude on her part.

In some of these cases - notably Silvia and Ryan - it seems possible that their attitudes towards the object or content of their faith is conflicted. For example, perhaps Silvia has a negative attitude to

10. Jesus transformed water into wine.

while also having other positive attitudes towards the proposition. According to PT, faith that $p$ requires desire or approval of $p$, or a belief that $p$ is desirable or good; PT does not say that faith that $p$ is incompatible with non-positive attitudes towards $p$. So, the examples can be brought into line with PT by assuming that positive attitudes are also in play.

We agree that individuals can be conflicted in this way, most clearly in the case of desires. Silvia might approve of Jesus' miraculous intervention at Cana while also disapproving of what he did. We also agree that if this is how things are with Silvia, then PT is consistent with the example. However, PT claims a necessary connection between faith and positive attitudes about its object or content. So, for the conflict defence to work, 
Silvia - along with individuals in any number of similar cases - must be conflicted. This, it seems to us, is less plausible than PT* without independent argument. Silvia may be conflicted, and this may be the most probable explanation of her attitude, but it does not seem necessary that she approve of (10) alongside her misgivings about it.

PT therefore runs into a number of problem cases. It seems that faith need not be accompanied by positive attitudes either when undergoing a crisis of faith or in much more mundane circumstances (such as [A]); positive attitudes need not extend to all contents or objects of one's faith (as in [B] and $[\mathrm{C}]$ ); faith also seems possible in cases where a positive attitude may not even be seen by the agent as appropriate (as in [D]).

\section{Modest Positivity Theory}

We have indicated our preference for $\mathrm{PT}^{*}$ which posits a contingent connection between faith and positive attitudes. But is there a more modest version of PT that is compatible with the counterexamples but retains the necessary link between faith and positivity? There seem to us two main options.

First, positivity theorists could attempt to find a more attenuated necessary connection between faith and positive attitudes towards its content or object. The onus is on the positivity theorist to flesh out the details of this connection. But since nobody has yet attempted this modification, and with a view to being constructive, here is a proposal of refined positivity theory:

(RPT) Necessarily, if R has faith that $p$ (or in $s$ ) then R desires that $p$ (or approves of $s$ ) or believes that $p$ is good (or that $s$ is good), or some relevantly connected faith judgement is accompanied by a desire or approval of its content or object or belief that its content or object is good.

This formulation is modelled on attempts to refine motivational internalism in metaethics, which are perhaps an object lesson in the difficulties of finding plausible attenuated necessary connections (see Björklund et al. 2012). The central idea behind RPT is that while there may be cases of individuals with faith that $p$ (or in $s$ ) without a corresponding positive attitude towards $p$ (or $s$ ), they must have a positive attitude to some proposition or object closely related to $p$ (or $s$ ). For example, Ellis may not think positively about Thomas' getting him to the venue on time, but he presumably does regard Thomas' timeliness or at least more generally 
Thomas' organisational abilities favourably. Is RPT, or something like it, defensible?

An initial problem for RPT is to specify what makes faith relevantly connected to a positive attitude. Suppose that Ellis has a high regard for Thomas' abilities as a cook and eagerly anticipates the culinary feast that Thomas will lay on for him. Ellis therefore appears to have a positive attitude that is connected to his faith in Thomas' timeliness, since both are concerned with his prospective meeting with Thomas. However, this is presumably not a relevant connection since his feelings about Thomas' cooking should not have a bearing on whether he has faith in Thomas' timeliness. Supporters of RPT will need to specify more closely the 'relevant connection' to avoid these problems. Second, RPT comes at a significant cost to plausibility. Once the positivity theorist has conceded that the arguments for PT considered in section one are unsuccessful, and that there are counterexamples to these theories, why continue to maintain that there is a distant necessary connection rather than conceding that there is no necessary connection at all? Third, there is an alternative to RPT compatible with the counterexamples that preserves the intuition that faith and positive attitudes are closely related: that there is a regular but contingent connection between faith and a positive attitude towards its content or object, i.e. PT*. This would account for the fact that we expect faith to be positive and that it usually is, while allowing that under certain circumstances it is not. Notably, the exploration of causal links between faith and positive attitudes has been the focus of a growing body of empirical investigation (Ögtem-Young 2018, Pargament 2010, and Pargament and Cummings 2010). We will say more about philosophical accounts of faith that make this relationship plausible in the following section.

It is useful to consider a specific way of developing an answer to the first objection, i.e. specifying the relevant connection needed for RPT. An appealing way of doing this is to posit a relationship between propositional and objectual faith. ${ }^{11}$ Take the example of Ellis. While he may not have a positive attitude towards the proposition that Thomas will get him to the venue on time, it is plausible that his propositional faith is based on faith in Thomas (or in Thomas' reliability), and that he thinks favourably of Thomas (or of Thomas' reliability). Similarly, while Martha may not have a positive attitude toward the proposition that the afterlife is predestined, she may have faith in the authority that inspired her propositional faith (the church, the Bible, God, etc.) and have a favourable attitude towards it. This suggests the following approach to defending refined positivity theory: in

${ }^{11}$ We would like to thank an anonymous referee for this journal for suggesting this example. 
cases where agents with propositional faith appear to lack a positive attitude towards the proposition in question, the propositional faith is based on an objectual faith with a content that is viewed positively.

The proposed ways of expanding the examples of Ellis and Martha to include objectual faith are plausible: their propositional faith may be inspired by objectual faith and, moreover, they may have a positive attitude associated with their objectual faith that they lack towards the proposition. This is, however, compatible with our preferred theory PT*, i.e. that faith is usually but only contingently associated with positive attitudes. A defence of PT or RPT will need to posit a necessary connection between propositional and objectual faith, that is, (non-positive) propositional faith is not merely causally related to (positive) objectual faith, but the former requires the latter. This is certainly not self-evident. If we look more broadly at the literature on faith, there is little, if any support for the view that there is a necessary relation between objectual and propositional faith. One potentially sympathetic voice in favour of the dependency of propositional faith on objectual faith is William Alston: 'It seems plausible that wherever it is clearly appropriate to attribute "faith that," there is a "faith in" in the background' (1996, 13). However, Alston appears to take the connection between propositional and objectual faith to be causal rather than necessary. Moreover, he offers this remark as an intuition about propositional faith rather than a substantive theory that he aims to defend. Making progress with the proposed defence of positivity theory, therefore, will require new arguments for dependency relations between propositional and objectual faith, which are yet to be forthcoming.

There is another fallback position available to positivity theory. This is to revise the account of the positive valence of faith whereby the positivity of faith is effectively guaranteed by faith internalism. As we saw in section two, if faith internalism (and Humean psychology) is true, then if R has faith that $p$ (or in $s$ ), $\mathrm{R}$ will have some desire-like state that will dispose her to in some way act on that faith. Now, if faith that $p$ (or in $s$ ) has this effect on R's plans and objectives, $p$ and $s$ make a difference to R. They make a difference for $\mathrm{R}$ because if $\mathrm{R}$ did not have faith that $p$ or in $s$ (or had faith in some other proposition or object) $\mathrm{R}$ would be differently motivated. To this extent, $p$ or $s$ matter to R. Accordingly faith internalism goes along with the following theory:

IPT (Internalist positivity theory): Necessarily, if $\mathrm{R}$ has faith that $p$ or in $s$ then $p$ or $s$ matter to R.

This, of course, is only tenuously a 'positivity' theory: it falls far short of the requirements of PT. The object or content of faith matters to R only in 
the sense that they make a difference to what she is motivated to do. As we saw in section two, this requires neither that R's motivating attitude is about the content or object of faith, nor that the attitude that motivates $\mathrm{R}$ is positive in the sense given by PT. Nevertheless, IPT does preserve a necessary connection between faith and some notion of positivity.

To see the potential appeal of IPT, it is useful to consider an argument from Howard-Snyder about the connection between faith and what we care about:

one cannot have faith that something is so without at least some tendency to feel disappointment upon learning that it's not so. That's because one can have faith that something is so only if one cares that it is so; and one can care that something is so only if one has some tendency to feel disappointment upon learning that it's not so. (Howard-Snyder 2013, 360)

Now, the connection between caring and a disposition to feel disappointment, offered here as a priori, seems to us misplaced. In some of the examples we considered in section three (notably Ellis and at least some examples of those with crises of faith) the connection looks doubtful. Here are two more examples. Suppose my son enters the sack jumping race at a local fete. I have faith that he is going to win. However, I learn that the prize for second place - a chocolate dinosaur - would please him far more than the Snakes \& Ladders game reserved for the winner (a copy of which he already has). He comes in second. Am I disappointed? Not even a little bit. This isn't because I didn't care that he would win while he was in the race or lacked faith that he would win. Rather, when he came in second, I ceased to have those attitudes and felt delighted (and maybe a little relieved) that he secured the prize he would prefer. Second, suppose I support a minor English football team at the low end of the National League. I recognise their many weaknesses but nevertheless have faith that they will manage to stay in the league and avoid relegation. It turns out that this does not happen. Instead, through a serious of extraordinary victories they secure a place in the higher English Football League. Am I disposed to be disappointed that they didn't stay in the same league? Clearly not. I am delighted they did even better than I had faith that they would.

Our point in drawing attention to Howard-Snyder's argument, however, is not for the connection he makes between faith and disappointment but the one between faith and caring. This connection is intuitively plausible but can be secured by IPT rather than PT: agents with faith care about the content or object of their faith because it matters to them. It matters because the content or object of their faith makes a difference to their motivations 
and what they plan to do. IPT, therefore, preserves an intuitive connection between faith and what the agent cares about.

IPT offers a viable fallback position by conceding the problematic aspects of PT, i.e., that the agent with faith requires a positive attitude towards the object or content of faith. As such, IPT escapes the counterexamples considered in section three that target this feature of PT. However, the 'positivity' of faith proposed by IPT derives from its impact on the motivational profile of agents that have faith. As such, IPT glosses faith internalism. Even if IPT is true, therefore, PT* is still needed to account for the connection between faith and one's approvals or positive evaluative judgements of the object or content of faith.

\section{Faith and True Grit}

We have argued that PT is false and instead endorsed (a) PT*, which posits a contingent connection between faith and positive attitudes, and (b) IPT, which connects faith and what matters to the agent with faith, in a way that follows from faith internalism. In this concluding section we will focus on some widely recognised, necessary properties of faith - that we will call true grit - that explain why faith should usually go along with positive attitudes, that is, why we would expect $\mathrm{PT}^{*}$ to be true. We will also argue that the examples considered in section two that purportedly lent support to PT can be explained by true grit rather than necessarily being accompanied by a positive attitude. ${ }^{12}$

As a starting point, it seems platitudinous that faith is not fickle. Someone who has faith that $p$ or faith in $s$ does not give up on $s$ or reject $p$ on the least reason to do so. Even if it is not acted on, a disinclination to give up on the object of faith seems one of the minimal necessary requirements for either objectual or propositional faith. Unsurprisingly, this idea shows up in most theories of faith, albeit under various guises: Bishop (2007), for instance, talks of 'commitment', Buchak (2017) 'steadfastness', HowardSnyder (2013) 'resilience', Kvanvig (2013) 'retention', Malcolm and Scott (2017) 'resistance', Matheson (2018) 'grit', and McKaughan (2018) 'perseverance'. One cannot have faith without in some way and to some extent sticking with the object of faith. Can we specify this disposition in a less metaphorical way, while preserving its platitudinousness?

\footnotetext{
${ }^{12}$ To the best of our knowledge, the expression grit, and the psychological literature associated with it (Duckworth et al. 2007), was first connected with the resilience of faith in a workshop presentation by Malcolm (2017). The first published work to make the connection was Matheson (2018).
} 
It is useful to consider a comparable literature in the social sciences where the notions of grit and, in particular, resilience have been explored (for recent overviews, see Bourbeau 2018; Jacelon 1997; Luthar et al. 2000; and Stewart and Yuen 2011), as well as where the connections between faith and resilience have been to the fore (see Pargament 2010; Pargament and Cummings 2010; Ögtem-Young 2018). This literature has admitted several characterisations of resilience, four of which look particularly relevant: the ability of an agent to 'bounce back' from a setback (Block and Thomas 1955), to 'adapt' to challenging circumstances by changing various attitudes and behaviours (Zautra et al. 2010), to 'persist' or exhibit 'staying power' (Masten et al. 1990), and to 'resist' the challenges presented by adverse circumstances (Rutter 2006). How might these be applied to psychological attitudes such as faith? Suppose an agent $\mathrm{S}$ has some attitude $\mathrm{A}$ under circumstances $\mathrm{C}$ that challenge or provide a reason for her to not have that attitude. The four characterisations of resilience suggest four corresponding ways in which $\mathrm{S}$ might be resilient with respect to $\mathrm{A}$ in $\mathrm{C}$ :

i. Bouncing Back: $\mathrm{S}$ is disposed to regain A after its loss as a result of C.

ii. Adaptation: $\mathrm{S}$ is disposed to modify her thinking and other attitudes to retain $\mathrm{A}$ in response to $\mathrm{C}$ that would otherwise cause her not to have A.

iii. Persistence: $\mathrm{S}$ is disposed to persist in exhibiting A in $\mathrm{C}$.

iv. Resistance: $\mathrm{S}$ is disposed to resist, at least to some extent, factors that would lead her to cease having A.

Faith could exhibit resilience in any of these ways. Suppose, for instance, I have faith in a friend's honesty, but I am presented with compelling evidence that he has acted dishonestly. Even if I lose my faith for a while, I may be (i) disposed to regain it later, or I may be (ii) inclined to change other attitudes - such as my views about the credibility of the source of the challenging evidence - to preserve my faith, or I may be (iii) disposed to continue to voice my conviction that my friend is honest in the face of this contrary evidence, or I may be simply (iv) disposed to be unpersuaded by that evidence (at least up to a point).

There is much more to say about the merits of these analyses of resilience but since our focus is on faith, it is (iv) - the resistance analysis - that seems to us the most promising. There are two reasons for this. First, (iv) is the least demanding of the four analyses: anybody who rebounds, adapts or persists in their attitudes in $\mathrm{C}$ thereby satisfies (iv) by resisting factors that would undermine A. Indeed, (i), (ii) and (iii) can each be seen as ways of resisting C: by adaptation, resistance or rebounding. Second, (i), (ii) and 
(iii) each face counterexamples. Someone might lose their faith without any inclination to regain it: 'I used to have faith in democracy as the best political system but after the political turbulence of last couple of years I've given up on the idea'. Similarly, while (ii) and (iii) - adaptation and persistence - may often characterise faith, neither one seems necessary. I may maintain my faith in a sports team but substantially change the manner in which I voice and act on that faith after my team undergoes a crushing defeat. I thereby adapt but do not persist in my earlier behaviours. In contrast, my faith may exhibit a degree of persistence but not be adaptable. I may be disposed to continue enthusiastically to support my team after various defeats, but not disposed to adapt my behaviour and attitudes to preserve my faith in the event of a major loss. So, in general, (iv) is successful because it does not restrict the ways in which $\mathrm{S}$ may be disposed to resist $\mathrm{C}$ with respect to her faith. The concept of resistance - discussed in the social sciences but hitherto not explicitly considered in philosophy - provides us with a helpfully minimal analysis of the kind of resilience that faith is widely taken to exhibit.

Can we say more about the challenging circumstances C? Discussion has tended to focus in particular on counterevidence to the truth of the propositional content of faith (Howard-Snyder 2013, 367-68; Buchak 2017; Matheson 2018; McKaughan 2018), less so on non-epistemic factors (though see examples from Howard-Snyder 2017 for non-epistemic examples of resilience). ${ }^{13}$ But faith goes along with resisting practical and psychological challenges. Consider, for instance, the demands of having faith in a society in which public expressions of faith are liable to be met with persecution and mistreatment. Sustaining faith in such a context incurs a practical cost: it is difficult to do and carries with it significant risks. This is, of course, a somewhat extreme case; faith does not have to be so resilient that it persists even under these circumstances. However, faith must be able to withstand some practical costs: one does not have faith in someone if one is disposed to defame them in exchange for an Oreo Bar. Additionally, one can have faith in someone who behaves in an exasperating and emotionally wearing manner. Again, faith need not require a heroic degree of determination and steeliness. But it does need to exhibit some degree of resistance to psychological pressures. One does not have faith that democracy is good if one is disposed to change one's mind about it because of the tiresome and provocative behaviour of one democratically elected leader. In general, faith disposes the faithful agent

\footnotetext{
${ }^{13}$ In the social psychology literature on 'grit', Duckworth et al. (2007) point to non-epistemic factors, but when grit is addressed in recent analytic philosophy, the focus is clearly on resisting epistemic reasons (Morton and Paul 2019).
} 
to withstand practical, emotional and psychological costs as well as contrary evidence. ${ }^{14}$

Since we are looking for a minimal, widely acceptable, and necessary property of faith, we will remain pluralists about the specification of the attitude of faith itself. For example, on a doxastic theory of propositional faith, faith disposes the agent to resist pressures (evidential, practical or psychological) to disbelieve the propositional content of faith; on a nondoxastic theory (e.g. Alston 1996) the attitude in question may be acceptance. On a trust theory of objectual faith (e.g. McKaughan 2016), the attitude will be a disposition to resist evidential, practical or psychological factors to break one's trust with the object of faith; on the theory that objectual faith is a goal-directed attitude (e.g. Kvanvig 2013), the agent will resist evidential, practical and emotional pressures to give up on that objective. We will remain neutral on these contentious areas of debate.

Drawing the elements of this theory together, we propose that it is necessary that faith disposes the agent to resist, to some extent, giving up on the object or content of faith (be it trust of or allegiance to the object, or a belief or support of the proposition, etc.) in response to epistemic, psychological or practical pressures to do so. For convenience we will call this property of faith true grit. ${ }^{15}$ Faith is true in the sense that it exhibits an allegiance or attachment to the object or content of faith (which may be characterised differently as belief, acceptance, trust, commitment, etc.); it is gritty in the sense that it is a disposition to resist (to some extent) challenging circumstances that would undermine that allegiance or attachment.

True grit is a distinct property from the positivity of faith. Someone with true grit is undeterred in their commitments by evidential, practical and psychological factors but they are not thereby invariably positive in their attitudes about the object or content of their faith. One may exhibit true grit without approving of or having a positive evaluative belief about the object of faith. On the other hand, a positive attitude toward $p$ (or about $s$ ) and true grit commonly go along with each other, as $\mathrm{PT}^{*}$ predicts. The most

\footnotetext{
${ }^{14}$ Although it is not central to our argument, the notion of contrary evidence needs more careful handling than it is sometimes given. If I have access to incontrovertible evidence that $p$ is true I will be unmoved by counterevidence to this belief. However, we usually take faith to be characterised by resistance to counterevidence that is not counterbalanced by the evidential resources at the agent's disposal. (For more discussion of the idea that faith 'goes beyond the evidence', see Buchak 2012; Malcolm 2020).

${ }^{15}$ We use this well-worn expression not with the aim of making a connection with established theories of grit in the social science, or existing accounts of faith that focus on grit as a salient property, but simply as a familiar expression to cover the minimal properties of faith that we are positing.
} 
straightforward way in which someone might have true grit towards an object or proposition is to desire or positively evaluate that object or the truth of that proposition, where these desires and beliefs have a causal role in sustaining one's resistance to circumstances C. For example, the resilience needed for faith that God will save us will be strengthened by the desire that God will save us or the judgement that this is a valuable thing. Positive attitudes towards the object or content of faith bolster one's resistance reasons to give up on that object or disbelieve that content. The true grit of faith, therefore, fits well with PT*.

Can true grit also explain the examples used to support PT? Let us take three. First, why do we find cases of faith like (11) but not like (12)?

\section{Peter has faith that Franz will give up smoking. \\ 12. Peter has faith that Franz will continue smoking.}

Buchak proposes that the absence of a positive attitude towards Franz continuing to smoke explains the difference. But this isn't convincing. Suppose that Peter wishes Franz ill and believes that Franz's death would be a good thing; suppose he also believes that Franz's continuing to smoke raises the chances of this happening. Even with the requisite positive desires and beliefs in place, that Franz will continue to smoke still looks like an odd thing for Peter to have faith about. True grit does better: it is the peculiarity of someone having an attitude of true grit towards Franz continuing to smoke that accounts for why (12) seems an odd candidate for faith. The circumstances in which (12) might be true are ones in which Peter persists, for example, in maintaining that Franz will continue to smoke despite evidence that he has given up. That is, where Peter exhibits the true grit he needs for faith.

Why do we find instances of faith like (13) but not (14)?

13. I have faith that I will give up smoking.

14. I have faith that I will continue smoking.

Not, it seems, because of anything to do with positivity. There is nothing unusual about a desire to smoke nor, unfortunately, about a desire to continue to smoke. So, the presence or absence of a positive attitude does not explain why (14) is an odd case. True grit does. To commit to give up smoking, for many, requires resolve in the face of a variety of pressures: putting aside the evidence of past failures to stop, determination to give up despite the nagging need to smoke; practical avoidance of circumstances in which one will be tempted to change one's mind. In contrast (14), except under unusual circumstances, is not a suitable subject of true grit. Indeed, 
it is the reverse: typically, someone doesn't need any resilience to believe that they will continue to smoke since they just need to give in to it.

Why do we find instances like (15) but not (16)?

15. Peter has faith that he will survive cancer.

16. Peter has faith that he will die of cancer.

According to the positivity theory, it is because the latter, unlike the former, is not something about which an agent usually has a positive attitude. Equally, however, the proposition that one will die of cancer is not usually something that people take a gritty attitude towards. For example, we do not usually find someone determined to uphold the judgement that they have cancer in the face of evidence that the diagnosis should be overturned. In contrast, we do find agents that have cancer with a gritty attitude towards their survival. For example, someone may be disposed to persist with this attitude when confronted with increasingly negative prognoses and the practical and emotional challenges that come with the worsening condition.

Now, it could be objected that we often find people who commit to gloomy assessments, of which Peter's judgement in (16) is an extreme case, and are gritty in maintaining those assessments. They are pessimists. Doesn't this show that we still need to appeal to positivity to explain why such pessimistic commitments do not count as faith? Not so. First, there is nothing about pessimistic judgements that requires they should be gritty. For example, someone who favours pessimistic beliefs or assumptions simply because they think those beliefs are true or those assumptions prudent, does not thereby hold to those beliefs or assumptions grittily. The kind of pessimistic judgement that satisfies true grit is less commonplace. The gritty pessimist would be disposed to, for example, disregard plausible contrary evidence to their beliefs, persist with the beliefs in the face of emotional and practical pressures to adopt less gloomy judgements, and so on. Second, PT does not exclude individuals from having faith in pessimistic beliefs: PT is a constraint on the kinds of attitudes required for faith, not on their content. For example, someone may form a pessimistic judgement about the future but also desire or in some way to approve of that outcome. Notably, for the reasons already given for the connection between true grit and positivity, we should expect that someone who is gritty in their pessimistic judgements will regard them positively. Neither true grit nor PT, therefore, exclude the possibility of faith in pessimistic judgments. 
Another purported advantage of the positivity theory is that a positive attitude distinguishes merely believing something from having faith in it. A difference between belief in ghosts and faith in ghosts, or between belief and faith that Trump will win a second term in 2024, is that the faith attitudes must be accompanied by a positive view of their objects. Here too, the true grit theory provides a simpler explanation of the contrasting cases without needing to appeal to positivity. For example, to have faith in ghosts or faith that Trump will win a second term in 2024 requires true grit - that is to resist a variety of countervailing considerations - whereas belief in these matters can be surrendered merely on the basis of evidence that it is not true.

These considerations suggest that even if we put aside the objections to PT, the appeal to positivity as an explanation of the examples used to support PT may be dispensable in favour of one that appeals to true grit. Moreover, in some examples, such as (11) and (12), true grit appears to provide a better explanation of the intuitive difference than positivity.

\section{REFERENCES}

Alston, William P. 1996. 'Belief, Acceptance, and Religious Faith'. In Faith, Freedom, and Rationality, edited by J. Jordan and D. Howard-Snyder, 3-27. Lanham: Rowman \& Littlefield.

Andrews, Frances. 2016. 'Introduction'. In Doubting Christianity: The

Church and Doubt, edited by Frances Andrews, Charlotte Methuen, and Andrew Spicer. Studies in Church History 52. Cambridge: Cambridge University Press.

Audi, Robert. 2011. Rationality and Religious Commitment. New York: Oxford University Press.

Bishop, John. 2007. Believing by Faith: An Essay in the Epistemology and Ethics of Religious Belief. Oxford: Clarendon Press.

Björklund, Fredrik, Gunnar Bjornsson, John Eriksson, Ragnar Francén Olinder, and Caj Strandberg. 2012. 'Recent Work on Motivational Internalism'. Analysis 72 (1): 124-37.

https://doi.org/10.1093/analys/anr118.

Björnsson, Gunnar, Caj Strandberg, Ragnar Francén Olinder, John Eriksson, and Fredrik Björklund, eds. 2015. Motivational Internalism. Oxford Moral Theory. New York: Oxford University Press.

Block, Jack, and Hobart Thomas. 1955. 'Is Satisfaction with Self a Measure of Adjustment?' The Journal of Abnormal and Social Psychology 51 (2): 254-59. https://doi.org/10.1037/h0048246. 
Bourbeau, Philippe. 2018. 'A Genealogy of Resilience'. International Political Sociology 12 (1): 19-35.

https://doi.org/10.1093/ips/olx026.

Buchak, Lara. 2012. 'Can It Be Rational to Have Faith?' In Probability in the Philosophy of Religion, edited by Jake Chandler and Victoria S. Harrison, 225-48. Oxford: Oxford University Press. https://doi.org/10.1093/acprof:oso/9780199604760.003.0012.

2014. 'Rational Faith and Justified Belief'. In Religious Faith and Intellectual Virtue, edited by Laura Frances Callahan and Timothy O'Connor, 49-73. Oxford: Oxford University Press. https://doi.org/10.1093/acprof:oso/9780199672158.003.0003.

2017. 'Faith and Steadfastness in the Face of Counter-Evidence'.

International Journal for Philosophy of Religion 81 (1-2): 11333. https://doi.org/10.1007/s11153-016-9609-7.

Duckworth, Angela L., Christopher Peterson, Michael D. Matthews, and Dennis R. Kelly. 2007. 'Grit: Perseverance and Passion for Long-Term Goals.' Journal of Personality and Social Psychology 92 (6): 1087-1101. https://doi.org/10.1037/00223514.92.6.1087.

Durà-Vilà, Glòria. 2016. Sadness, Depression, and the Dark Night of the Soul. London; Philadelphia: Jessica Kingsley Publishers.

Faigin, Carol Ann, and Kenneth I. Pargament. 2011. 'Strengthened by the Spirit: Religion, Spirituality, and Resilience through Adulthood and Aging'. In Resilience in Aging: Concepts, Research, and Outcomes, edited by Barbara Resnick, Lisa P. Gwyther, and Karen A. Roberto, 163-80. New York, NY: Springer. https://doi.org/10.1007/978-1-4419-0232-0_11.

Howard-Snyder, Daniel. 2013. 'Propositional Faith: What It Is and What It Is Not'. American Philosophical Quarterly 50 (4): 357-72.

2017. 'Markan Faith'. International Journal for Philosophy of Religion 81 (1): 31-60. https://doi.org/10.1007/s11153-0169601-2.

- 2019. 'Can Fictionalists Have Faith? It All Depends'. Religious Studies 55 (4): 447-68.

https://doi.org/10.1017/S0034412518000161.

Jacelon, Cynthia S. 1997. 'The Trait and Process of Resilience'. Journal of Advanced Nursing 25 (1): 123-29.

https://doi.org/10.1046/j.1365-2648.1997.1997025123.x.

Jackson, Elizabeth. 2020. 'Belief, Faith, and Hope: On the Rationality of Long-Term Commitment'. Mind, no. fzaa023.

https://doi.org/10.1093/mind/fzaa023.

Kaufmann, Walter Arnold. 1958. Critique of Religión and Philosophy. Princeton: Princeton University Press. 
Kolodiejchuk, Brian. 2007. Mother Teresa - Come Be My Light: The Revealing Private Writings of the Nobel Peace Prize Winner. New York: Doubleday.

Kvanvig, Jonathan L. 2013. 'Affective Theism and People of Faith'. Midwest Studies in Philosophy 37 (1): 109-28. https://doi.org/10.1111/misp.12003.

Luthar, Suniya S., Dante Cicchetti, and Bronwyn Becker. 2000. 'The Construct of Resilience: A Critical Evaluation and Guidelines for Future Work'. Child Development 71 (3): 543-62.

Malcolm, Finlay. 2017. 'Perseverance and the Value of Faith: Lessons from the Psychology of Grit'. In . University of Manchester.

2020. 'The Moral and Evidential Requirements of Faith'. European Journal for Philosophy of Religion 12 (1): 117-42. https://doi.org/10.24204/ejpr.v0i0.2658.

Malcolm, Finlay, and Michael Scott. 2017. 'Faith, Belief and Fictionalism'. Pacific Philosophical Quarterly 98 (S1): 257-74. https://doi.org/10.1111/papq.12169.

Masten, Ann S., Karin M. Best, and Norman Garmezy. 1990. 'Resilience and Development: Contributions from the Study of Children Who Overcome Adversity'. Development and Psychopathology 2 (4): 425-44. https://doi.org/10.1017/S0954579400005812.

Matheson, Jonathan. 2018. 'Gritty Faith'. American Catholic Philosophical Quarterly. 2018.

https://doi.org/10.5840/acpq201858152.

Mckaughan, Daniel J. 2013. 'Authentic Faith and Acknowledged Risk: Dissolving the Problem of Faith and Reason'. Religious Studies 49 (1): 101-24. https://doi.org/10.1017/S0034412512000200.

McKaughan, Daniel J. 2016. 'Action-Centered Faith, Doubt, and Rationality'. Journal of Philosophical Research 41 (9999): 7190. https://doi.org/10.5840/jpr20165364.

. 2018. 'Faith through the Dark of Night: What Perseverance amidst Doubt Can Teach Us about the Nature and Value of Religious Faith'. Faith and Philosophy. 2018.

https://doi.org/10.5840/faithphil2018327101.

Morton, Jennifer M., and Sarah K. Paul. 2018. 'Grit'. Ethics 129 (2): 175203. https://doi.org/10.1086/700029.

Noveck, Ira. 2018. Experimental Pragmatics: The Making of a Cognitive Science. Cambridge: Cambridge University Press. https://doi.org/10.1017/9781316027073.

Ögtem-Young, Özlem. 2018. 'Faith Resilience: Everyday Experiences'.

Societies 8 (1): 10. https://doi.org/10.3390/soc8010010.

Pargament, Kenneth I., and Jeremy Cummings. 2010. 'Anchored by Faith: Religion as a Resilience Factor'. In Handbook of Adult 
Resilience, edited by J. W. Reich, A. J. Zautra, and J. S. Hal, 193210. New York, NY, US: The Guilford Press.

Plantinga, Alvin. 2000. Warranted Christian Belief. New York: Oxford University Press.

Pojman, Louis. 1986. 'Faith without Belief?' Faith and Philosophy 3 (2):

157-76. https://doi.org/10.5840/faithphil19863213.

Rutter, Michael. 2006. 'Implications of Resilience Concepts for Scientific

Understanding'. Annals of the New York Academy of Sciences 1094: 1-12. https://doi.org/10.1196/annals.1376.002.

Schellenberg, J. L. 2005. Prolegomena to a Philosophy of Religion. Ithaca, N.Y.: Cornell University Press.

Stewart, Donna E., and Tracy Yuen. 2011. 'A Systematic Review of Resilience in the Physically Ill'. Psychosomatics 52 (3): 199209. https://doi.org/10.1016/j.psym.2011.01.036.

Swinburne, Richard. 2001. 'Plantinga on Warrant'. Religious Studies 37

(2): 203-14. https://doi.org/10.1017/S0034412501005601.

Zautra, Alex J., John Stuart Hall, and Kate E. Murray. 2010. 'Resilience:

A New Definition of Health for People and Communities'. In Handbook of Adult Resilience, edited by A. Reich, J. Zautra, and J. S. Hall, 3-29. New York, NY, US: The Guilford Press. 